\title{
A obsolescencia da literatura de cordel: aspectos de escrita e oralidade
}

The obsolescence of cordel literature: aspects of writing and orality

Valdemar Valente Júnior

Universidade Federal do Rio de Janeiro

Resumo: Este texto visa discutir a importância da literatura de cordel como elemento cultural arcaico ainda presente na cultura brasileira contemporânea. Na condição de parte integrante da cultura nordestina, tende a estabelecer uma relação estreita com seu povo, mas esbarra na inviabilidade artesanal de sua produção na atualidade. 0 crescimento do nível de interesse acerca da literatura de cordel em diferentes áreas dos estudos acadêmicos resulta da necessidade do cotejo dos elementos fundadores da cultura nordestina com o processo de globalização que abrange aspectos arcaicos e modernos a partir de um mesmo fluxo.

Palavras-chave: Cultura popular. Poesia. Folclore. Nordeste brasileiro. Regionalismo.

Abstract: This text aims to discuss the importance of cordel literature as an archaic cultural element present in contemporary Brazilian culture. As an integral part of the Northeastern culture, it tends to establish a close relationship with its people, but it runs up against the unfeasibility of its production at the present time. The growth of the level of interest about cordel literature in different areas of academic studies results from the need to compare founding elements of Northeastern culture with the process of globalization that encompasses archaic and modern aspects from the same flow.

Keywords: Popular culture. Poetry. Folklore. Brazilian northeast. Regionalism. 


\section{A expressão do povo}

Os elementos da cultura popular que insistem em permanecer inseridos no plano em expansão das mercadorias, na ordem do consumo capitalista, podem ser pensados a partir de um outro meio de inclusão. Se for considerado o período de apogeu do comércio dos folhetos de cordel, nas décadas de 1950 e 1960, quando as encomendas para parte do país seguem por via aérea, sua importância diminui significativamente. Em seguida, com sua consolidação nos meios de comunicação de massas, especificamente da televisão, a exemplo da recente novela "Cordel en-

Valdemar Valente Júnior cantado", da Rede Globo, há uma queda na procura por folhetos, o que atinge a produção das tipografias nordestinas e das xilogravuras, que chegam à estagnação. A isto podemos acrescentar os lugares de excelência sem substituição, no que se refere a poetas como Leandro Gomes de Barros e João Martins de Ataíde. A literatura de cordel, mesmo submetida a tentativas de revitalização, teria para sempre a referência de seus mestres, a exemplo de outros tantos, sendo seus folhetos sucessivamente editados, o que aponta para a importância destes nomes entre seus seguidores.

Em torno da literatura de cordel configura-se uma feição que viabiliza seu consumo pela classe média urbana. Por sua vez, em vista de sua força expressiva, alguns poetas urbanos, além de compositores de música popular, tentam apropriar-se de seus arquétipos para reproduzi-los em circuito comercial. Cabe dizer que ambas as tentativas resultam em malogro, uma vez que as realizações da indústria cultural, por sua deliberada posição de condenar à obsolescência aquilo que produz, não dão conta de que essa manifestação ainda permaneceria restrita a uma espécie de cadinho, conservando-se no limite de sua originalidade. Além disso, os meios acadêmicos procuram franquear-lhe o acesso e, por último, o espaço da televisão dedica-lhe uma faixa de seu horário nobre, colocando-a em evidência em situações ficcionais.

A utilização da literatura de cordel pela classe média letrada ainda se mantém no plano de sua manifestação arcaica, mesmo que lhe sugira a atualização do que não tem como ser corrigido. Não obstante o aproveitamento do cordel pela televisão, essa investida em nada alteraria a situação de que desfruta, por não haver nenhuma mudança significativa em sua configuração. Do mesmo modo, a apropriação da literatura de cordel pela música popular possui os requintes de um fari- 
saísmo mal-intencionado, a partir de quem busca fazer sucesso através de poetas como Patativa do Assaré e Otacílio Batista. Também seu emprego por poetas ligados à militância política, que tentam politizá-la, conseguiria reproduzir arremedos engendrados de maneira bisonha. As tentativas de integrá-la a uma condição de participação política esbarram no fato concreto de que sua sobrevivência ou derrocada dependem dela própria:

\begin{abstract}
Uma das lições a tirar da experiência que alguns poetas urbanos fizeram, quando tentaram se servir da forma exterior e da linguagem típica da poesia de cordel para dar-lhe um conteúdo participante, "corrigi-la" ideologicamente e ao mesmo tempo valer-se de sua teórica penetração de massa, é a de que a autêntica poesia popular é inimitável e incorrigível. Basta comparar qualquer das coisas que assim se perpetraram com a obra dos verdadeiros cantadores do Nordeste, para verificar de imediato a imensa superioridade desta sobre os produtos contrafeitos dos imitadores bem-intencionados - a superioridade dos "profissionais" populares sobre os "amadores" cultos e citadinos (CAMPOS, 1978, p. 257).
\end{abstract}

Assim, a atitude de protegê-la não altera a dinâmica de sua presença no mercado cultural. Nas capitais do Nordeste, especificamente em Salvador, Recife e Fortaleza, mais que um patrimônio integrado à vida das pessoas, em sua dimensão cotidiana, a literatura de cordel converte-se em curiosidade especulativa do turismo predatório. As barracas armadas em mercados populares, centros culturais e feiras de artesanato reiteram a perda de seu significado, o que repercute em seu aspecto decorativo, a partir de quem adquire um souvenir esvaziado de sua função. Diante disso, resta-lhe continuar a existir no plano das transformações que levam as mercadorias à completa obsolescência. A isso, Renato Ortiz acrescenta: "Muitas vezes temos tendência a imaginar as sociedades modernas como um organismo anômico. A fragmentação seria sua característica principal" (1998, p. 134). Por sua vez, o esforço de quem busca reanimar sua energia, ainda que com boa intenção, não se faz suficiente para resolver o problema de uma manifestação cultural que já teve seu momento supremo, independentemente do apoio que se supõe necessário.

\section{A obsolescência da literatura de cordel}


Diante disso, reitera-se a irrelevância de querer tratar a literatura de cordel como espécie em extinção, garantindo-lhe o sentido de reserva ecológica. Os autores de cordel caminham na direção de uma mudança para a qual não se pode medir a dimensão, cabendo indagar até que ponto essa mudança incorrerá na dispersão completa de seus valores absolutos. Por esse meio, Ivan Cavalcanti Proença interfere: "O poeta popular ali está, sob toda uma gama de propaganda, comunicação de massa, e tudo que hoje compõe a quase imposta aldeia global" (1977, p. 105). Quer isto venha a ocorrer, o tempo se incumbi-

Valdemar rá de dar à literatura de cordel outra função, relativa à incorporação Valente Júnior de seus recitais e cantorias, bem como de seus folhetos, pelas redes de computadores, observando-se um princípio a que os bens culturais acabam por seguir. Desse modo, a informatização de um universo pré-industrial tende a concorrer para que seus objetos, em estágio de obsolescência, acabem por perder sua eficácia em nome de uma ordem de coisas que promove a estandardização da cultura. Tudo faz crer que as alternativas em torno da literatura de cordel tendam a amoldar-se, por questões de sobrevivência, à inevitável incursão nos meios eletrônicos de comunicação.

O sistema econômico, a cada estágio de tempo, recicla uma série de produtos culturais e condena alguns outros em nome do que parece aguardar em uma lista que tem pressa em dar conta de cada acontecimento. Assim, as disputas entre o antigo e o novo estabelecem trocas de lugares e papéis, implicando na condenação de modelos que podem recuperar sua posição anterior, ainda que isso não represente uma regra. Por outro lado, muitas manifestações arcaicas desaparecem sem que se saiba quando pode ocorrer seu retorno. Assim, "as transformações associadas à modernidade libertaram o indivíduo de seus apoios estáveis nas tradições e nas estruturas" (HALL, 2004, p. 25). Por isso, a literatura de cordel não tem como assegurar sua presença como produto de massas, uma vez que sua configuração, para efeito do consumo, apresenta-se precária, não havendo como ser revista sua eficácia nos termos de sua articulação como mercadoria em processo de expansão. A exigência de sucessivas medidas de atualização que a torne viável, com relação ao público, não tem como incorporar seus elementos arcaicos, a partir de sua própria forma, sendo preciso que se proceda um mecanismo de agenciamento de sua incursão no mercado de consumo. 


\section{Espaços de reconhecimento}

O interesse que a literatura de cordel desperta no âmbito dos estudos culturais representa seu principal campo de força. Decorre disto sua presença no mercado artístico, se for pensado o aspecto artesanal de sua divulgação, e a série de antologias, muitas delas reunindo em edições fac-similares o que de melhor se consigna em um corpus referente a seus autores mais expressivos. Essas antologias resultam do interesse que a literatura de cordel ainda desperta nas novas gerações, a partir de folhetos que se tornaram clássicos no imaginário nordestino. Assim, os núcleos culturais interessados na preservação dessa memória, a exemplo de fundações e editoras, concorrem para que seja dado a esse acervo um tratamento capaz de manter vivo o que ainda resta de sua tradição. Por isso, o inventário desse material configura-se como objeto digno da A obsolescência da literatura de cordel atenção que lhe é dedicada.

Além disso, a literatura de cordel representa ao longo dos últimos anos uma fonte de reflexão para estudiosos, sugerindo a consolidação de seu nível de importância, no âmbito da pesquisa acadêmica, como matéria relevante da cultura do país. Seu ressurgimento atende a outro tipo de solicitação, não mais em função da conotação lúdica e informativa que lhe caracteriza, mas da teorização de seu lugar no âmbito da poesia popular. Por esse meio, Paul Zumthor ajuda a agravar o debate: "Todo texto poético é, nesse sentido, performativo, na medida em que aí ouvimos, e não de maneira metafórica, aquilo que ele nos diz" (2007, p. 54). Sua função educativa implica no fato de que muitos nordestinos se alfabetizaram através dos folhetos impressos. Essa afirmação cede espaços à sua qualificação de rudimento arcaico a serviço de um campo de estudo, decorrendo daí sua valorização como matéria a que se agregam postulados teóricos fundamentais. Nesse sentido, algumas universidades nordestinas como a UEFS, na Bahia, e a UFPB, na Paraíba, desenvolvem pesquisas envolvendo a literatura de cordel. Isso corresponde à sedimentação de uma escala de conhecimento do que a literatura de cordel pode representar, não mais em vista de sua condição pitoresca, mas de seu peso cultural, apresentado a outro público, desta vez interessado em aprofundar diferentes planos de estudo acerca de sua dimensão teórica.

Esse fenômeno popular passa a atender a linhas de pesquisa que conceituam sua importância como objeto de cultura. Esta sistematização compreende um nível de interesse que não se atém ao fato de não 
ser mais a literatura de cordel uma manifestação plena, tendo em conta sua presença como fragmento cultural que sobrevive. A esse respeito, Maria José F. Londres comenta: "É de supor que a fonte escrita seja responsável pelas histórias que não revelam traços regionais nacionais e guardam as características das narrativas europeias" (1983, p. 41). Assim, seu estudo coloca na ordem do dia a posição relativa a um princípio de oralidade que já não desfruta de seu apogeu, na condição de material de origem ibérica que resiste, mesmo diante das demandas da técnica em desacordo com as formas artesanais que ainda têm efeito. A literaValdemar tura de cordel como matéria de pesquisa se faz notar a cada publicação Valente Júnior que surge como meio de propor outra dimensão à sua situação na história da cultura. A importância adquirida, a partir de sua inclusão na esfera acadêmica, corresponde à sua elevação a um plano específico do conhecimento que lhe fora negado ao longo do tempo.

Assim, a impressão de folhetos e a composição de xilogravuras passam a integrar um amplo conjunto de atividades, através de palestras, recitais e cantorias. No entanto, a venda dos folhetos não mais representa uma garantia de renda ao cordelistas. Os espaços abertos pela televisão, se forem consideradas apenas as emissoras estatais, concorrem para a permanência, em outros moldes, de sua condição essencial no âmbito da cultura. A esse respeito, Octávio Ianni acrescenta: "Em geral, a cultura dominante, burguesa, concebe largos setores da sociedade como população, isto é, uma coletividade de trabalhadores" (1996, p. 150). Contudo, é preciso que se pense nessas propostas a partir da precariedade de que padecem as instituições culturais no país. A literatura de cordel intensifica seu prestígio de arte popular recorrendo a um plano de elevação possível como meio de dialogar com outros círculos de cultura. A isso se acresce o fato de sua aceitação persistir como um rudimento da cultura popular do Nordeste, apesar de poder expandir seu raio de ação na direção das classes sociais que não se constituem em seu público, o que não a exclui de sua condição em relação à literatura canônica: 


\begin{abstract}
e misterioso cânon para cujo conhecimento não fomos iniciados. Iniciação que é uma longa capitalização de contatos seculares com o espírito da própria manifestação da cultura coletiva (CASCUDO, 1978. p. 26).
\end{abstract}

A tradição na literatura de cordel tende a amalgamar-se à ideia de um sistema cultural que, ao reconhecer o esgotamento de suas formas, reserva-lhe um espaço de reconhecimento onde sua configuração histórica parece estagnar-se. No entanto, não há como impedir que a literatura de cordel siga seu caminho, mesmo que a condição presente manifeste-se de maneira desigual, com relação à produção de alguns de seus mais significativos autores. Parece inequívoco que sua antiga situação não tenha como ser recuperada, cabendo aos cordelistas do presente A obsolescência da literatura de cordel um esforço no sentido de dotar essa manifestação de condições materiais que, se por um lado apresentam-se mais satisfatórias, do ponto de vista técnico, por outro discrepam de seu sentido de existência quanto ao cumprimento de funções sociais que se encontram esvaziadas. Ao lado disso, a vontade de amparar a literatura de cordel esbarra em sua condição de patrimônio imaterial, confirmando sua situação de elemento da cultura que já não reúne condições próprias de permanência.

A ocupação de um lugar no mundo contemporâneo consiste na exigência de serem patenteados elementos arcaicos que passam a ser reconhecidos. Tanto nos meios da cultura de massas quanto nos círculos acadêmicos, a literatura de cordel ratifica um estágio do capitalismo que não mais contempla a informalidade comercial dos folhetos, sendo que sua venda persiste por conta de um valor que se agrega à sua condição folclórica, o que lhe soa como um termo acessório. o lugar da literatura de cordel, para além dos elementos de uma sociedade arcaica, que por vezes não sabe lidar com os meios da mídia eletrônica, necessita de outros padrões de reconhecimento, diferentes do que representa a venda no varejo de seus folhetos. A dimensão dos acontecimentos que parece condenar a literatura de cordel à completa condição de esvaziamento encontra força nos pontos inerentes a seu aproveitamento a partir de outras regras.

O desdobramento dessas manifestações não é passível de indagação, cabendo entender as transformações do tempo como responsáveis pelo que não tem como situar-se de outro modo, senão no que se encontra em observância ao que exige a ordem das coisas. A literatura de cor- 
Valdemar Valente Júnior

del passa a assumir lugares de excelência acadêmica, no plano das dissertações e teses de que é tema constante. Ao usufruir desse espaço, sua afirmação crítica, do ponto de vista de um fenômeno sociológico, tem enfatizado o valor estético de alguns de seus mais expressivos autores. Daí situar-se como um meio de ligação entre a cultura oral e a cultura letrada em um nível de qualidade que faz dela um exemplo de elaboração formal dos mais importantes. A posição de reconhecimento que passa a ocupar coincide com o declínio de seu lugar na cultura popular, com a inevitável decadência dos meios de produção de que se serve.

A crítica brasileira concorre para que a literatura de cordel passe a ter uma recepção que antes não lhe seria possível, sendo uma referência cultural em processo, o que antecipa o estudo de sua passagem do arcaico ao moderno. Em vista disso, sua configuração de poesia tende a receber um olhar abrangente, não levando em consideração suas particularidades, onde efetivamente reside seu inegável valor. O desvio do foco de atenção sobre sua excelência não omite seu sentido coletivo como meio de participação de uma coletividade que nela encontra um mínimo de retorno. Esse retorno apresenta-se em sua forma possível, se for pensado um conjunto de poemas narrativos que configuram o espaço de imaginação de um povo duramente castigado pela desigualdade social. Por isso, sua colaboração como tema de pesquisa acadêmica amplia sua atuação em um contexto que faz dela uma ferramenta de análise que se presta a entender de que maneira sua expressão mais profunda ainda teima em existir.

\section{0 arcaico e o moderno}

O encantamento presente nos folhetos de cordel retoma a origem de sua chegada ao Brasil. Se for pensado o fato de que com os portugueses chegam elementos da cultura ainda ligados à Idade Média, o século XVI está longe de definir um princípio de cultura. $O$ que aqui aporta configura-se no conjunto de narrativas que reconstitui parte da cultura medieval, a partir da exploração de elementos mágicos que se solidificaram no repertório de adivinhas, parlendas e chistes que atravessam o tempo até sua dispersão completa, com o predomínio dos meios de reprodução técnica. Os símbolos de oralidade trazidos para o Brasil nos navios portugueses encontram um terreno propício a sua fecundação como matéria geradora de uma riqueza cultural que fixa suas bases na possibilidade de servir à imaginação popular, sugerindo-lhe formas narrativas. 
A Idade Média suscita diferentes respostas à carga de repressão moral que lhe pesa. Desse modo, aos interditos da Igreja Católica se contrapõem as peripécias que burlam suas exigências em nome de uma flexibilidade de cunho espontâneo que povoa a memória popular. Personagens da literatura de cordel, como João Grilo e Pedro Malasartes, propõem a adaptação dos fragmentos da cultura oral ibérica ao que se confirma como base da cultura do Nordeste brasileiro. Se for pensado o fato de que essas manifestações sugerem uma correspondente necessidade de circulação de matéria ficcional, tendo em vista a precariedade econômica da região, esse princípio de oralidade faz da poesia popular um instrumento de cultura. Assim, "para entender o alcance e a extensão dos fenômenos da oralidade, não se pode deixar de lado este circuito impresso, as coleções de brochuras, edições populares e popularizantes" (FERREIRA, 1995,

A obsolescência da literatura de cordel p. 46). Dito isso, os mitos arcaicos encontrados nas narrativas anônimas do povo ibérico passam a integrar uma unidade de pensamento, criando suas normas a partir de um contato que se estreita, em decorrência da circulação dos folhetos de cordel como modalidade escrita.

A aventura humana que tem lugar com os confrontos na Europa medieval dá origem a poemas narrativos que se configuram como canções de gesta e novelas de cavalaria. Essas expressões da poesia oral estendem sua presença às populações que nelas concebem exemplos, no âmbito dos conflitos que implicam diretamente em suas vidas. As divisões e as lutas por territórios constituem a ação de muitas narrativas, sobretudo se for pensado de que forma esses eventos assumem um lugar na imaginação popular, ao serem recriados de forma poética. A Idade Média estende-se em expectativa à chegada dos colonizadores, para quem o Renascimento inexiste como uma etapa da cultura, persistindo os ecos da criação oral que se populariza em um território onde ainda não se identificam representações da memória como instrumento de fruição de um princípio estético:

\footnotetext{
Reproduzidos em pequenas brochuras, confeccionados em papel barato, os folhetos eram vendidos a preços acessíveis. Destinavam-se a um público heterogêneo sem perder de vista o fato de que, no Brasil, a intimidade com o mundo da leitura e da escrita era privilégio de poucos. A leitura destes frágeis livros tinha finalidades diversas: ajudava a aliviar o fatigante trabalho agrícola, estava presente nos momentos de descanso quando as
} 
pessoas se reuniam para ouvir as narrativas em versos e as "histórias de Trancoso", e com as histórias de $\mathrm{ABC}$, contribuía para iniciar os leitores no restrito universo da escrita. Esta característica da literatura de folhetos - a leitura coletiva em voz alta - contrapõe-se a outras formas de expressão literária em que o texto é fruído solitariamente e em silêncio (MELO, 2010, p. 59).

Por conta da memória popular trazida para o Brasil, as lendas europeias avançam no tempo, impregnando de informações medievais Valdemar o século XX nordestino. Como fator agravante, a situação de um povo Valente Júnior submetido à fome e à seca encontra referências nessas narrativas, na medida em que a penúria corrobora com as respostas encontradas em um imaginário que lhe atenua interditos de cunho moral e religioso. Nesse aspecto, não há como não se justificar que temas da literatura de cordel envolvendo personagens como a Donzela Teodora e Roberto do Diabo não sejam reminiscências de um tempo que alimenta a situação presente. "A investigação das sociedades arcaicas contribuiu, em troca, para que fosse percebida com maior transparência uma verdade que é também aplicável ao capitalismo: a interdependência entre o material e o simbólico" (CANCLINI, 1983, p. 77). Na condição de fragmentos de uma memória que se adensa ao imaginário do homem nordestino, o passado conserva-se na falta de promessas que garantam as condições presentes. Por isso, a tradição oral apresenta-se como um sucedâneo de configuração arcaica à inexistência de meios de atuação que lhes sejam contrários.

Assim, histórias de fadas e princesas encantadas aliam-se a temas como o dilúvio universal ou os sofrimentos de Jesus Cristo. O imaginário na literatura de cordel recorre a um repertório cujos princípios retomam sucessivos planos de memória, fundando-se em elementos que encontram dificuldade em sua renovação. $O$ contato do povo nordestino com a mitologia popular, aliada à forte presença do cristianismo, caminha com lentidão em direção à modernidade. Por isso, a literatura de cordel não abre mão de personagens como Antônio Silvino, Lampião e Padre Cícero, remetendo-se ainda a temas em completo desuso como Roldão e o Leão de Ouro ou a Morte dos Doze Pares de França. Por sua vez, manifesta o melhor de sua vitalidade quando estabelece relações de disputa entre seus autores, a exemplo da Peleja de João Ataíde com Leandro Gomes ou da Peleja de Cego Aderaldo com Zé Pretinho, em que os cantadores recuperam a tradição medieval do desafio em versos. 
A literatura de cordel vive seu melhor momento quando a sociedade industrial ainda não invadira todos os seus espaços na forma do capitalismo que se amplia oferecendo produtos culturais que lhe inibem o vigor. Um momento significativo dessa transformação ocorre em paralelo à exploração dos temas medievais, quando a literatura de cordel se urbaniza, a partir de poetas situados nas capitais do Nordeste, a exemplo de Cuíca de Santo Amaro, que, vivendo em Salvador, coloca seus folhetos a serviço das causas da cidade, instigando polêmicas e suscitando debates. A isso agrega-se o fato de dela recorrer a uma demanda de mercado que conquista os espaços urbanos como resultado do processo da concentração da cultura rural nas capitais em expansão, o que de algum modo implica em sua preservação.

Daí uma nova configuração da literatura de cordel decorrer A obsolescência da literatura de cordel da chegada do homem do campo, tangido de suas áreas de origem, às cidades do Sudeste, com ênfase para o Rio de Janeiro e São Paulo. “A velocidade e a intensidade com que elementos tanto materiais quanto ideológicos agora circulam através de fronteiras nacionais criaram uma nova ordem de incerteza na vida da sociedade" (APPADURAI, 2009, p. 15). Nesses centros, busca inserir sua cultura na ordem de um processo de criação ao par das transformações do mundo contemporâneo, intervindo em assuntos mais abrangentes, a respeito de demandas sociais e políticas. Por sua vez, o mercado de folhetos sofre um duro revés, com a venda da Tipografia São Francisco, em Juazeiro do Norte, responsável pela impressão da maioria dos folhetos clássicos. Disso decorre a descaracterização do que a literatura de cordel representa como campo de força da cultura nordestina, ainda que busque resistir através da criação da Lira Nordestina, que também acaba por sucumbir, em vista do processo de esvaziamento em curso na vida cultural da região.

O interesse pela literatura de cordel atinge pontos específicos. Sua importância como elemento da cultura nordestina diminui consideravelmente. Se forem pensadas as formas através das quais a industrialização, aliada à comunicação de massas, vêm operando na sociedade brasileira, mais especificamente nas comunidades rurais, a defesa a essas invasões encontram-se extremamente fragilizadas. Por isso, ao contrário do que ocorreu em um passado não muito recente, quando uma grande maioria atingida pelo analfabetismo usufruía da comunicação oral em contato com cantorias, nos mercados e feiras do Nordeste, a literatura de cordel emancipa-se, no sentido de que ainda representa 
a criação de uma escola cujos alunos tentam seguir o caminho de seus mestres, adaptando a experiência passada a uma perspectiva presente, ao tentar conquistar a dimensão de seu extremo valor.

\section{REFERÊNCIAS}

APPADURAI, Arjun. 0 medo ao pequeno número: ensaio sobre a geografia da raiva. Traduzido por Ana Goldberger. São Paulo: Iluminuras, Itaú

Valdemar Cultural, 2009.

Valente Júnior

CAMPOS, Augusto de. Um dia, um dado, um dedo. In: Verso, reverso, controverso. São Paulo: Perspectiva, 1978.

CANCLINI, Néstor García. As culturas populares no capitalismo. Traduzido por Cláudio Novaes Pinto Coelho. São Paulo: Brasiliense, 1983.

CASCUDO, Luis da Camara. Literatura oral no Brasil. Rio de Janeiro: José Olympio, 1978.

FERREIRA, Jerusa Pires. Matrizes impressas da oralidade. In: BERND, Zilá e MIGOZZI, Jacques (org.). Fronteiras do literário: literatura oral e popular Brasil/França. Porto Alegre: Editora da UFRGS, 1995.

HALL, Stuart. A identidade cultural na pós-modernidade. Traduzido por Tomaz Tadeu da Silva e Guaracira Lopes Louro. Rio de Janeiro: DP\&A, 2004.

IANNI, Octávio. A ideia de Brasil moderno. São Paulo: Brasiliense, 1996.

LONDRES, Maria José F. Cordel: do encantamento às histórias de lutas. São Paulo: Duas Cidades, 1983.

MELO, Rosilene Alves de. Arcanos do verso: trajetórias da literatura de cordel. Rio de Janeiro: 7Letras, 2010.

ORTIZ, Renato. Mundialização e cultura. São Paulo: Brasiliense, 1998. 
PROENÇA, Ivan Cavalcanti. A ideologia do cordel. Rio de Janeiro: Editora Brasília, 1977.

ZUMTHOR, Paul. Performance, recepção, leitura. Traduzido por Jerusa

Pires Ferreira e Suely Fenerich. São Paulo: Cosac Naify, 2007.

- Recebido em julho / 2017

- Aceite em agosto / 2017

A obsolescência

da literatura de

cordel 
